\title{
In memory of Professor Zdzisława Świerczyńska, Ph.D., D.Med.Sc.
}

The highest reward for a person's toil is not what they get for it, but what they become by it (John Ruskin 1819-1900)

She departed forever on 17 May 2016. She left a memory, and not just a formal memory of the Head of the Department of Microbiology and Serology of the Institute of Rheumatology, but the team of grateful former and current employees of the department, who will remember her as she was our teacher and promoted our professional development and research.

After working at the Silesian Medical Academy she began on 1 November 1962 working in the Institute of Rheumatology in Warsaw, initially as an assistant professor in the Department of Microbiology and Serology. After achieving the rank of associate professor on 19 April 1963 she became the Head of the Department of Microbiology and Serology from 1 July 1963 and directed it until her retirement (1 January 1987). She obtained the title of professor

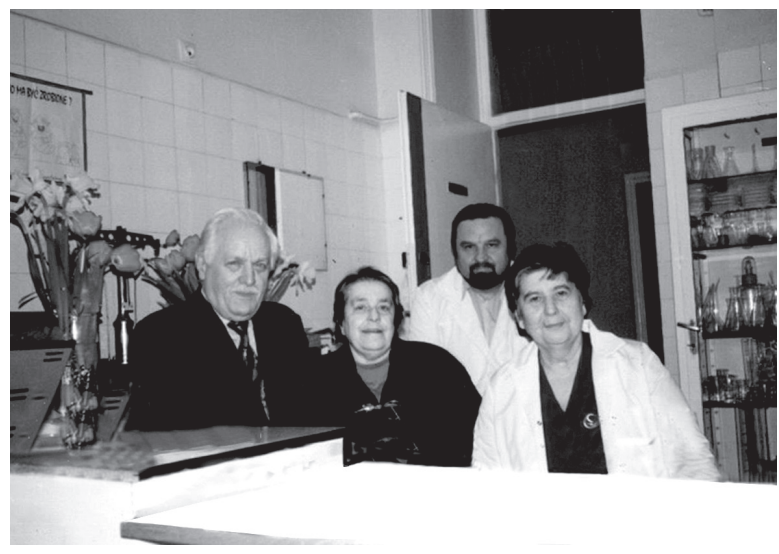

From the right Dr Genowefa Woźniczko-Orłowska, Prof. Zdzisława Świerczyńska, Prof. Stanisław Luft, in the second row Prof. Jakub Ząbek on 1 March 1974, and the title of full professor on 1 November 1982. Undoubtedly, one-year scholarships in academic centers in Toronto in 1966 and Buffalo (USA) in the years 1984-1985 were a valuable source of her qualifications and teaching methods.

All these functions as well as the degrees of Professor Zdzisława Świerczyńska had a close relationship with the development of scientific activities of the department, especially in the field of immune diagnosis in clinical rheumatology.

We valued her contribution, consistency and kindness in encouraging our - employees of the Department of Microbiology and Serology - scientific development (scientific meetings, publications, participation in congresses and conferences, degrees granted).

We owe her our memory and gratitude.

On behalf of students and colleagues Professor Stanisław Luft, Ph.D., D.Med.Sc. Head of the Department of Microbiology and Serology from 1 January 1988 to 31 December 1994 